\title{
Books by Q.H. Vuong at Harvard University Library
}

Library Catalog

Access:

March 2, 2021
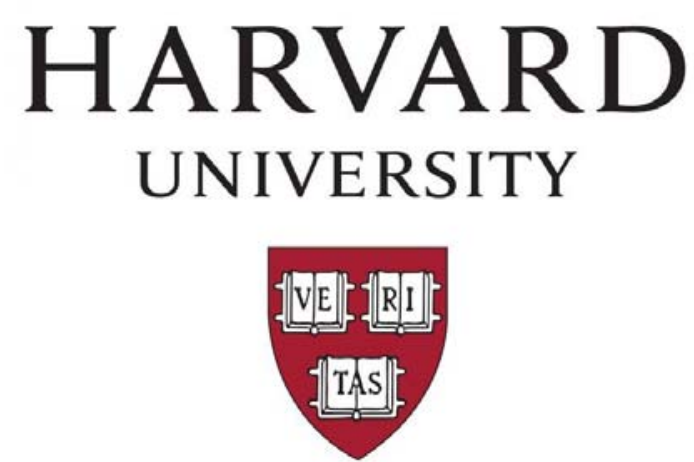

Harvard University

Querying URL:

https://hollis.harvard.edu/primo-explore/search?search-bannerinput=Quan\%2OHoang\%2OVuong\&tab=everything\&vid=HVD2\&lang=en_US\&offset=0\&q uery=any, contains,Quan\%20Hoang\%2OVuong

The search results in two books by Q.H. Vuong, which follow.

1. Kinh tế Việt Nam: thăng trầm và đột phá HOLLIS number: 990120291470203941 (Harvard Yenching Library) Permalink: http://id.lib.harvard.edu/alma/990120291470203941/catalog 2. Bằng chứng cuộc sống: suy nghĩ về phát triển bền vững Việt Nam HOLLIS number: 990145805910203941 (Harvard Yenching Library) Permalink: http://id.lib.harvard.edu/alma/990145805910203941/catalog 
Kinh tế Việt Nam : thăng trầm và đột phá

Phạm, Minh Chính. / Hà Nội : Nhà xuất bản Chính trị quốc gia

2009

Available at Harvard Yenching Library Offsite Storage (HC444 .P446 2009) >

Details

Title

Kinh tế Việt Nam : thăng trầm và đột phá

Attribution

Phạm Minh Chính, Vương Quân Hoàng.

\section{Author / Creator}

Phạm, Minh Chính. >

\section{Published}

Hà Nội : Nhà xuất bản Chính trị quốc gia, 2009.

\section{Description}

xxx, 554 p. : ill. ; $23 \mathrm{~cm}$.

\section{Summary}

Portraits of strategy and development of economic in Vietnam.

\section{Language}

Vietnamese

\section{Notes}

Includes bibliographical references (p. 539-549) and index.

\section{Subjects}

Structural adjustment (Economic policy) -- Vietnam -- History >

Economic development -- Vietnam -- History >

Vietnam -- Economic conditions -- 1975- >

\section{Author / Creator}

Vương, Quân Hoàng. >

\section{Creation Date}

2009

\section{HOLLIS number}

990120291470203941

\section{Permalink}

http://id.lib.harvard.edu/alma/990120291470203941/catalog

\section{Source}

HVD - Core

\section{Other search terms}

Economic policy >

Economics >

Statics and dynamics (Social sciences) > 
OPTIONS: Scan \& Deliver (book chapter)

Harvard Yenching Library Offsite Storage HC444 .P446 2009

HOURS \&

Hide Notes \& Holdings

Availability:

( 1 available, 0 requests )

Action note committed to retain 20181001 in perpetuity ReCAP Shared Collection

1 - 1 of 1 Records

BARCODE

TYPE

POLICY

DESCRIPTION

STATUS

32044114529878

Book

Please sign in

Available 
Bằng chứng cuộc sống : suy nghĩ về phát triển bền vững Việt Nam Bạch, Ngọc Chiến [author] / Hà Nội : Nhà xuất bản Chính trị quốc gia - Sự thật 2015

Available at Harvard Yenching Library Offsite Storage (HC444.Z9 E5 2015 ) >

Details

Title

Bằng chứng cuộc sống : suy nghĩ về phát triển bền vững Việt Nam

Attribution

Bạch Ngọc Chiến, Vương Quân Hoàng.

\section{Author / Creator}

Bạch, Ngọc Chiến [author] >

\section{Published}

Hà Nội : Nhà xuất bản Chính trị quốc gia - Sự thật, 2015.

\section{Description}

255, a-w pages : illustrations (some color), charts ; $22 \mathrm{~cm}$

\section{Language}

Vietnamese

\section{Notes}

Includes bibliographical references (pages A-P) and index.

\section{Subjects}

Sustainable development -- Vietnam >

Vietnam -- Economic policy -- 1975- >

\section{Author / Creator}

Vương, Quân Hoàng [author] >

\section{Creation Date}

2015

\section{HOLLIS number}

990145805910203941

\section{Permalink}

http://id.lib.harvard.edu/alma/990145805910203941/catalog

\section{Source}

HVD - Core

\section{Other search terms}

Economic development >

\section{Get It}


OPTIONS: Scan \& Deliver (book chapter)

Harvard Yenching Library Offsite Storage HC444.Z9 E5 2015

Hide Notes \& Holdings

Availability:

( 1 available, 0 requests )

Action note committed to retain 20181001 in perpetuity ReCAP Shared Collection

1 - 1 of 1 Records

BARCODE

TYPE

POLICY

DESCRIPTION

STATUS

32044139940779

Book Please sign in

Available 


\section{References:}

[1] Phạm Minh Chính, Vương Quân Hoàng. (2009). Kinh tế Việt Nam: Thăng trầm và Đột phá. Nxb Chính trị Quốc gia, Hà Nội.

[2] Bạch Ngọc Chiến, Vương Quân Hoàng. (2000). Bằng chứng cuộc sống: Suy nghĩ về phát triển bền vững Việt Nam. Nxb Chính trị Quốc gia, Hà Nội. 